\title{
The application of novel Ir-NHC polarization transfer complexes by SABRE
}

Cite as: J. Chem. Phys. 151, 244201 (2019); https://doi.org/10.1063/1.5128091

Submitted: 16 September 2019 . Accepted: 04 December 2019 . Published Online: 23 December 2019

Sara Hadjiali, Marvin Bergmann, Alexey Kiryutin, et al.

\section{COLLECTIONS}

Paper published as part of the special topic on Spin Chemistry
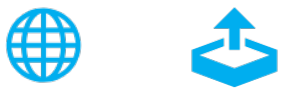

\section{ARTICLES YOU MAY BE INTERESTED IN}

A simple and cost-efficient technique to generate hyperpolarized long-lived ${ }^{15} \mathrm{~N}-{ }^{15} \mathrm{~N}$ nuclear spin order in a diazine by signal amplification by reversible exchange The Journal of Chemical Physics 152, 014201 (2020); https://doi.org/10.1063/1.5132308

Fast destruction of singlet order in NMR experiments

The Journal of Chemical Physics 151, 234203 (2019); https://doi.org/10.1063/1.5131730

\section{SABRE polarized low field rare-spin spectroscopy}

The Journal of Chemical Physics 152, 184202 (2020); https://doi.org/10.1063/5.0002412

\section{Challenge us.}

What are your needs for periodic signal detection?

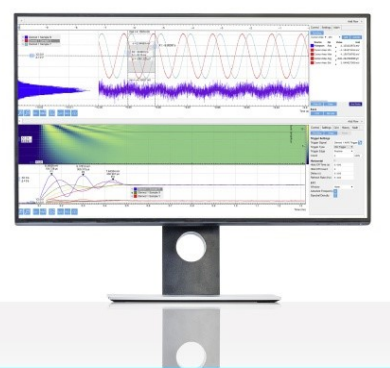




\title{
The application of novel Ir-NHC polarization transfer complexes by SABRE
}

\author{
Cite as: J. Chem. Phys. 151, 244201 (2019); doi: 10.1063/1.5128091 \\ Submitted: 16 September 2019 - Accepted: 4 December 2019 • \\ Published Online: 23 December 2019
}

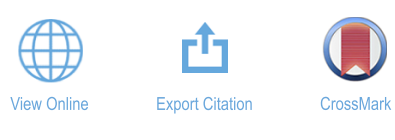

\author{
Sara Hadjiali, ${ }^{1}$ Marvin Bergmann, ${ }^{\top}$ Alexey Kiryutin, ${ }^{2}$ Stephan Knecht, ${ }^{1}$ Grit Sauer, ${ }^{1}$ Markus Plaumann \\ Hans-Heinrich Limbach, ${ }^{1,4}$ (D) Herbert Plenio, ${ }^{1}$ (D) and Gerd Buntkowsky ${ }^{1,}$

\begin{abstract}
AFFILIATIONS
${ }^{7}$ Eduard-Zintl Institute for Inorganic and Physical Chemistry, TU Darmstadt, Darmstadt 64287, Germany

${ }^{2}$ International Tomography Center, Institutskaya 3A, Novosibirsk and Novosibirsk State University, Pirogova 2, Novosibirsk 630090, Russia

${ }^{3}$ Medical Faculty, Institute for Biometrics and Medical Informatics, Otto-von-Guericke University Magdeburg, 39120 Magdeburg, Germany

${ }^{4}$ Freie Universität Berlin, Institut für Chemie und Biochemie, Takustr. 3, D-14195 Berlin, Germany
\end{abstract}

Note: This paper is part of the JCP Special Topic on Spin Chemistry.

a)Email: gerd.buntkowsky@chemie.tu-darmstadt.de

\begin{abstract}
In recent years, the hyperpolarization method Signal Amplification By Reversible Exchange (SABRE) has developed into a powerful technique to enhance Nuclear Magnetic Resonance (NMR) signals of organic substrates in solution (mostly via binding to the nitrogen lone pair of N-heterocyclic compounds) by several orders of magnitude. In order to establish the application and development of SABRE as a hyperpolarization method for medical imaging, the separation of the Ir-N-Heterocyclic Carbene (Ir-NHC) complex, which facilitates the hyperpolarization of the substrates in solution, is indispensable. Here, we report for the first time the use of novel Ir-NHC complexes with a polymer unit substitution in the backbone of N-Heterocyclic Carbenes (NHC) for SABRE hyperpolarization, which permits the removal of the complexes from solution after the hyperpolarization of a target substrate has been generated.
\end{abstract}

Published under license by AIP Publishing. https://doi.org/10.1063/1.5128091

\section{INTRODUCTION}

To overcome the low sensitivity of Nuclear Magnetic Resonance (NMR) spectroscopy and Magnetic Resonance Imaging (MRI), a number of hyperpolarization techniques, which create population differences far larger than the thermal equilibrium Boltzmann polarization, were developed. The most prominent examples are Dynamic Nuclear Polarization (DNP), ${ }^{1-6}$ Spin Exchange Optical Pumping (SEOP), ${ }^{7-9}$ and Parahydrogen Induced Polarization (PHIP). ${ }^{10-14}$ The latter employs a hydrogenation reaction of an unsaturated bond with parahydrogen $\left(\mathrm{pH}_{2}\right)$, a nuclear spin isomer of dihydrogen $\left(\mathrm{H}_{2}\right)$. All these techniques have in common that they produce a nonequilibrium spin-level population, which leads to strongly enhanced Magnetic Resonance (MR) signals. Signal Application By Reversible Exchange (SABRE) $)^{15-17}$ is a variant of the PHIP technique, which employs a reversible chemical reaction of $\mathrm{pH}_{2}$ and a substrate, usually $\mathrm{N}$-heterocyclic compounds, with suitable Iridium (Ir) complexes. This polarization transfer complex (PTC) (Fig. 1) ${ }^{18,19}$ converts the singlet spin order of the $\mathrm{pH}_{2}$ into substrate magnetization through scalar couplings in a proper magnetic field. An advantage of SABRE compared to PHIP is that it creates polarization without chemical modification of the substrate, thus it is not necessary to incorporate hydrogen into unsaturated molecules. ${ }^{20-23}$

This way, the NMR signal of substrates can be amplified by several orders of magnitude. SABRE is of particular interest in medical diagnostic applications, as many biologically relevant molecules, e.g., many drugs, contain N-heterocyclic compounds and are therefore potential targets for SABRE applications. ${ }^{24-26}$ However, one obstacle for the use of SABRE in a clinical setting is the toxicity of the employed heavy metal containing PTC. To overcome this hurdle, two approaches have been investigated in the past. ${ }^{2}$ 
A)

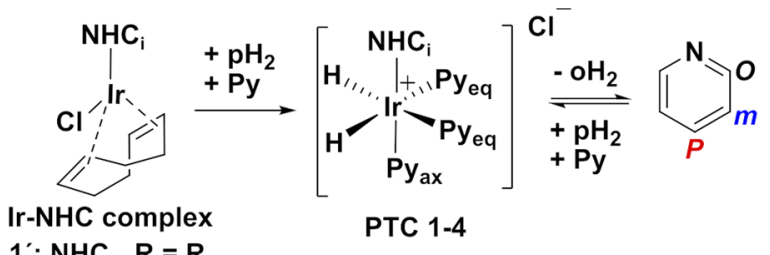<smiles>[R]C1=CN(c2c(C)cc(C)cc2C)CN1c1c(C)cc(C)cc1C</smiles><smiles>[R2]CCCCN1C(=O)C2C3C=CC(O3)C2C1=O</smiles><smiles>[R2]CCN1C(=O)C2C(OC(C(C)C)C3C(=O)N(CCC)C(=O)C23)C(=O)N1CCC</smiles><smiles>[R]CCCCCCCOCC</smiles>

FIG. 1. (a) Schematic representation of the SABRE hyperpolarization process. First, the Ir-NHC complex $\left(1^{\prime}, 2^{\prime}, 3^{\prime}, 4^{\prime}\right)$ is activated in the presence of pyridine (Py) by exposure to $\mathrm{pH}_{2}$. The process yields the polarization transfer complex (PTC 1-4), in which both $\mathrm{pH}_{2}$ and $\mathrm{Py}$ are reversibly bound. Therefore, the spin order transfer from $\mathrm{pH}_{2}$ to $\mathrm{Py}$ is facilitated. (b) Structures of the used $\mathrm{NHC}_{\mathrm{i}}$ with different substituents $\left(\mathrm{R}_{1-4}\right)$ at the $\mathrm{NHC}$ backbone. These $\mathrm{NHC}_{i}$ are employed in the Ir-NHC complexes, as well as in the PTC 1-4.

First, the removal of homogeneous PTC by complex scavenging, ${ }^{27}$ and second, the immobilization of complexes on suitable support material. $^{28,29}$

The molecular structures of the PTC play an important role in the spin order transfer. ${ }^{31}$ Therefore, understanding the structure and chemistry of such complexes is necessary for improving the polarization. ${ }^{19,32,33}$ The currently most efficient PTC for SABRE hyperpolarization $\left[\operatorname{Ir}\left(\mathrm{NHC}_{1}\right) \mathrm{L}_{2} \mathrm{~S}\left(\mathrm{H}_{2}\right)\right]^{+}$complex $\left[\mathrm{NHC}_{1}\right.$ : IMes = 1,3-bis $(2,4,6-$ trimethylphenyl)imidazol-2-ylidene, $\mathrm{S}=$ solvent, $\mathrm{L}=$ substrate] was reported by Duckett et al. ${ }^{19}$ In 2017, Bergmann et al. published the synthesis and structure of Ir-N-Heterocyclic Carbene (Ir-NHC) complexes $\mathbf{2}^{\prime}, \mathbf{3}^{\prime}$, and $\mathbf{4}^{\prime}$ (Fig. 1). ${ }^{34}$ Compared to $\mathbf{1}^{\prime}$ (Fig. 1), the NHC backbone in $\mathbf{2}^{\prime}, \mathbf{3}^{\prime}$, and $\mathbf{4}^{\prime}$ is substituted with monomer or polymer units. The structural characteristics of PTC 1 (Fig. 1), which are decisive for its efficiency as PTC, ${ }^{19,26,31}$ were widely retained. However, in principle, PTC 2, PTC 3, and PTC 4 (Fig. 1) can be removed from the solution by nanofiltration due to the bulky substituent. ${ }^{35}$ As a result, the toxic complexes can be separated from the substrate. This is an important step toward biomedical applications of SABRE. ${ }^{18,26}$ The present paper aims to optimize the hyperpolarization of the ${ }^{1} \mathrm{H}$ pyridine $\left({ }^{1} \mathrm{H}\right.$-Py) signals using these new complexes. The suitability and efficiency of PTC 2, PTC 3, and PTC 4 (Fig. 1) as PTCs for SABRE hyperpolarization was tested. Several SABRE experiments with different deuterated solvents have been examined to find the most effective solvent. Furthermore, the field dependence of SABRE with these complexes was investigated. In addition, the substrate and PTC concentrations, which are important parameters for an efficient polarization transfer ${ }^{36}$ process, were investigated for these novel PTC.

\section{EXPERIMENTAL}

\section{Synthesis of catalysts}

$\mathbf{1}^{\prime}$ was synthesized according to the route of Savka and Plenio. ${ }^{37}$ The synthesis of the Ir-NHC complexes $\mathbf{2}^{\prime}, \mathbf{3}^{\prime}$, and $\mathbf{4}^{\prime}$ (Fig. 1) was described by Bergmann et al. ${ }^{34}$ and will not be repeated here.

\section{Automatized setup for measurements}

${ }^{1} \mathrm{H}-\mathrm{NMR}$ and ${ }^{1} \mathrm{H}-\mathrm{SABRE}$ spectra were recorded on a $500 \mathrm{MHz}$ Bruker Avance III NMR spectrometer system equipped with an 11.4 T Oxford standard bore magnet. The details of the automatized setup for SABRE application were described before. ${ }^{38}$ It allows for bubbling of two gases [e.g., 50\% parahydrogen enriched $\mathrm{H}_{2}$ and helium ( $\mathrm{He}$ ) gas for quenching the reaction] and applying vacuum for cleaning the connecting lines. SABRE field cycling was performed in the fringe field of the magnet employing an extension tube to the pneumatic Bruker sample lifting system. The extension tube has a set of regularly spaced holes, whose positions correspond to a dozen of fixed magnetic fields in the range from 5.5 to $12 \mathrm{mT}$. By opening and closing these holes the position in the fringe field for polarization transfer is chosen. For experiments where the polarization transfer field (PTF) was constant, the closest position to the expected optimum of $6.6 \mathrm{mT}$ was chosen. The whole timing scheme of the experiment, including gas bubbling, is controlled by the NMR pulse program ${ }^{38}$ [see electronic supplementary information (ESI)].

\section{Sample preparation}

Pyridine (Py) (anhydrous, 99.8\%) was purchased from SigmaAldrich and the various deuterated solvents such as methanol- $\mathrm{d}_{4}$ $(99.8$ at. $\% \mathrm{D})$, chloroform- $\mathrm{d}_{1}(99.8$ at. $\% \mathrm{D})$, tetrahydrofuran$\mathrm{d}_{8}\left(99.9\right.$ at. $\%$ D), acetonitrile- $\mathrm{d}_{3}\left(99.9\right.$ at. \% D), and acetone- $\mathrm{d}_{6}$ (99.9 at.\% D) were purchased from Eurisotop. All substances were used without further purification. The samples were prepared in $5 \mathrm{~mm}$ Pyrex ${ }^{\circledR}$ screw cap NMR tubes from Rototec-Spintec $\mathrm{GmbH}$. In order to generate the hyperpolarization, $\mathrm{pH}_{2}$ was passed through the sample at a pressure of 3 bars for $10 \mathrm{~s}$ in the desired polarization transfer field (PTF) and then moved into the detection field of $11.7 \mathrm{~T}$ (corresponding to a ${ }^{1} \mathrm{H}$ Larmor frequency of $500 \mathrm{MHz}$ ). The signal enhancement was quantified by a comparison of a ${ }^{1} \mathrm{H}$ SABRE and a relaxed ${ }^{1} \mathrm{H}$ NMR spectrum. The 
typical transfer time from the polarization to the detection field was $10 \mathrm{~s}$.

The samples used for the SABRE experiments consist of the substrate (here: Py), the Ir-NHC complexes (Fig. 1), and $\mathrm{pH}_{2}$. The activation process for all complexes took about $10 \mathrm{~min}$ and can be monitored by the change of color of the solution from yellow to transparent and by the presence of the ${ }^{1} \mathrm{H}$ signal of cyclooctane (chemical shift $\delta \approx 1.5 \mathrm{ppm}$ ). Additionally, the occurrence of hydride signals at around $-23 \mathrm{ppm}$ in the ${ }^{1} \mathrm{H}$-SABRE spectra confirms the formation of PTC (see ESI).

For the preparation of the concentration dependent SABRE experiments, stock solutions of $50 \mu \mathrm{l}$ Py with $950 \mu \mathrm{l}$ acetone- $\mathrm{d}_{6}$ or 20 $\mu \mathrm{l}$ Py with $980 \mu \mathrm{l}$ acetone- $\mathrm{d}_{6}$ were prepared. $10 \mu \mathrm{l}$ of the stock solution was then added to each of the samples repeatedly to increase the substrate concentration.

\section{RESULTS}

\section{Influence of the solvent}

Due to the good solubility of $\mathrm{pH}_{2}$ in methanol, methanol- $\mathrm{d}_{4}$ generally proves to be a very efficient solvent for SABRE experiments. ${ }^{31,39}$ However, $\mathbf{3}^{\prime}$ and $\mathbf{4}^{\prime}$ are poorly or not at all soluble in methanol- $\mathrm{d}_{4}$. In order to find a suitable solvent, a number of SABRE experiments with different deuterated solvents have been carried out (Table I). Using chloroform- $\mathrm{d}_{1}$ as solvent, only low signal amplification was achieved. This could be explained by the poor solubility of $\mathrm{H}_{2}$ in chloroform- $\mathrm{d}_{1}$, which leads to less $\mathrm{pH}_{2}$ being available for the SABRE reaction. ${ }^{39,40}$ Accordingly, solvent mixtures of chloroform- $\mathrm{d}_{1}$ and methanol- $\mathrm{d}_{4}$ were employed to increase the efficiency of the SABRE process. $\mathbf{2}^{\prime}$ was first dissolved in methanol- $\mathrm{d}_{4}$, then chloroform- $\mathrm{d}_{1}$ was added to the reaction solution (v/v 1:1). In comparison to pure chloroform- $\mathrm{d}_{1}$, the mixture of chloroform- $\mathrm{d}_{1}$ with methanol- $\mathrm{d}_{4}(\mathrm{v} / \mathrm{v}$ 1:1) shows an one order of magnitude increased signal enhancement as compared to pure chloroform- $\mathrm{d}_{1}$. This indicates that the strategy tested here, which takes into account the different solubilities of $\mathrm{pH}_{2}$ and of the IrNHC complexes in different solvents, can be used to optimize the signal amplification. Furthermore, $2^{\prime}$ was dissolved in acetone- $\mathrm{d}_{6}$, tetrahydrofuran- $\mathrm{d}_{8}$, and acetonitrile- $\mathrm{d}_{3}$ (Table I). Using acetonitrile$\mathrm{d}_{3}$ as a solvent, a complete activation of PTC 2 was not possible and only low enhanced Py signals were observed. This is not surprising as acetonitrile can efficiently coordinate to the SABRE complex on its own, making it a poor choice as a solvent, as it will competitively bind to the complex and effectively act as a large substrate pool, reducing the efficiency of the SABRE process. ${ }^{41-44}$ PTC 2 dissolved in tetrahydrofuran- $\mathrm{d}_{8}$ shows increased enhancements of the ${ }^{1} \mathrm{H}-\mathrm{Py}$ signals ( -35 for $o-\mathrm{Py},-36$ for $p$-Py, and -35 for $m$-Py) compared to methanol- $\mathrm{d}_{4}$ or chloroform- $\mathrm{d}_{1}$.

The best enhancement factors for PTC 2 were achieved in acetone- $\mathrm{d}_{6}$. Whereas the values (see Table II) for $p$-Py: $-274 \pm 6$ and $m$-Py $-262 \pm 6$ protons are very close to the values of PTC 1, the value for $o$-Py: $-158 \pm 6$ is interestingly only about $60 \%$ of the $o$-Py value of PTC $\mathbf{1}$. Since PTC $\mathbf{1}$ is the most efficient PTC known to date, these results clearly show the suitability of PTC 2 for SABRE.

\section{Influence of the polarization transfer field (PTF) on the SABRE efficacy}

It is known that the efficiency of polarization transfer in SABRE experiments depends strongly on the PTF. ${ }^{45-47}$ In order to achieve the maximum hyperpolarized ${ }^{1} \mathrm{H}$-signal enhancement for $\mathrm{Py}$, the influence of the PTF on the ${ }^{1} \mathrm{H}$-Py signal of PTC 2 was investigated using the solvents described in the previous section. The enhancement factors of the ${ }^{1} \mathrm{H}$-Py signals in the presence of PTC

TABLE I. List of deuterated solvents, which are utilized for SABRE experiments. The enhancement factors listed are for ${ }^{1} \mathrm{H}$ o-Py at the optimum PTF for the individual PTC.

\begin{tabular}{|c|c|c|c|c|c|c|}
\hline PTC & Methanol- $\mathrm{d}_{4}$ & Chloroform- $\mathrm{d}_{1}$ & Tetahydrofuran- $\mathrm{d}_{8}$ & Acetonitrile- $\mathrm{d}_{3}$ & Acetone- $\mathrm{d}_{6}$ & $\begin{array}{c}\text { Methanol- } \mathrm{d}_{4} / \text { chloroform- } \mathrm{d}_{1} \\
(\mathrm{v} / \mathrm{v} 1: 1)\end{array}$ \\
\hline 2 & -24 PTF: $6.2 \mathrm{mT}$ & $-1,35$ PTF: $7.1 \mathrm{mT}$ & -35 PTF: $8.6 \mathrm{mT}$ & No enhancement & -158 PTF: $5.8 \mathrm{mT}$ & -28 PTF: $6.2 \mathrm{mT}$ \\
\hline 3 & Insoluble & -19 PTF: $6.6 \mathrm{mT}$ & Insoluble & Insoluble & -21 PTF: $6.6 \mathrm{mT}$ & Insoluble \\
\hline 4 & Insoluble & -7 PTF: $6.6 \mathrm{mT}$ & Insoluble & Insoluble & -43 PTF: $6.6 \mathrm{mT}$ & Insoluble \\
\hline
\end{tabular}

TABLE II. Results of the solvent-dependent SABRE experiments at $6.6 \mathrm{mT}$ of free Py in the presence of PTC 1-4. The signal enhancements of PTC 1-4 are compared at the optimum concentrations of PTC and Py.

\begin{tabular}{lcccccr}
\hline \hline & & & & \multicolumn{2}{c}{$\varepsilon$ : Signal enhancement } \\
\cline { 5 - 6 } Nr. & PTC $(\mathrm{mM})$ & Py $(\mathrm{mM})$ & Solvent & $o$-Py & $p$-Py & $m$-Py \\
\hline $\mathbf{1}$ & 10.2 & 20.3 & Acetone-d & $-286 \pm 8$ & $-273 \pm 8$ & $-273 \pm 8$ \\
$\mathbf{2}$ & 0.7 & 10.3 & Acetone- $_{6}$ & $-158 \pm 6$ & $-274 \pm 6$ & $-262 \pm 6$ \\
$\mathbf{3}$ & 1.2 & 4.1 & Acetone-d & $-43 \pm 3$ & $-42 \pm 3$ & $-41 \pm 3$ \\
$\mathbf{4}$ & 0.2 & 45.6 & Acetone- $\mathrm{d}_{6}$ & $-21 \pm 1$ & $-21 \pm 1$ & $-21 \pm 1$ \\
\hline \hline
\end{tabular}


2 as a function of the PTF are depicted in Fig. 2 for the different solvents. For all solvents employed, the best enhancement factor was achieved in the low magnetic field range between $6 \mathrm{mT}$ and $8 \mathrm{mT}$. This range corresponds well with the theoretical and experimental values reported in the literature, ${ }^{19,26,31,41}$ which predict a maximum at about $6.5 \mathrm{mT}$. The best signal enhancement was realized for a PTF of approximately $6 \mathrm{mT}$ in acetone- $\mathrm{d}_{6}[\mathrm{Fig} .2(\mathrm{c})]$. For this reason, all following SABRE experiments of PTC 3 and PTC 4 were carried out in this field.
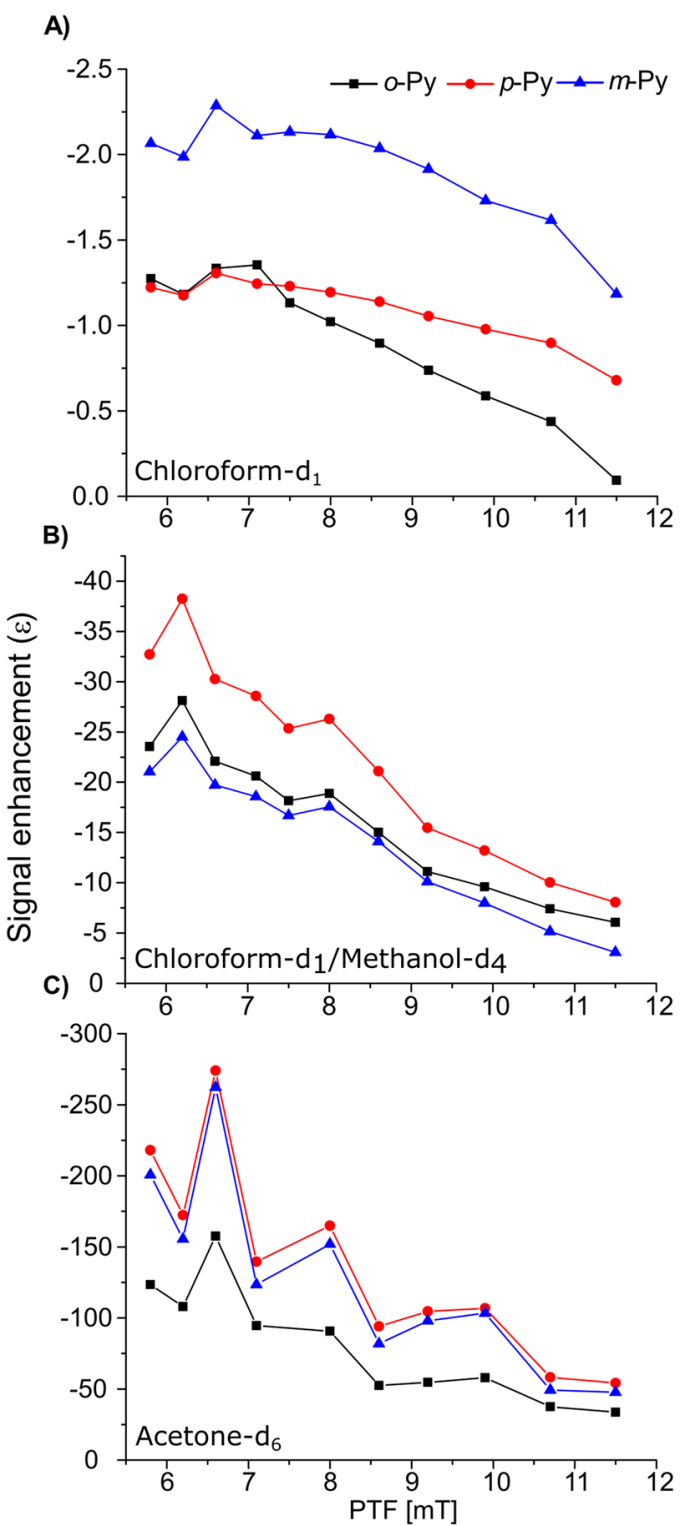

FIG. 2. Enhancement factors of the ${ }^{1} \mathrm{H}$-Py signals in the presence of PTC 2 as a function of the polarization transfer field (PTF) for the different solvents [(a): chloroform- $d_{1},(b)$ : methanol- $d_{4} / c h l o r o f o r m-d_{1}(v / v ~ 1: 1)$, and (c) acetone- $\left.d_{6}\right]$. The highest signal enhancement was achieved in the range between 6 and $8 \mathrm{mT}$.

\section{Influence of the concentrations of substrate and PTC}

It is known that the relative concentrations of the substrate and PTC have an influence on the exchange rates of the reactions in Fig. 1, and thus on signal enhancement achieved in SABRE experiments. ${ }^{26}$ PTC 3 and PTC $\mathbf{4}$ are novel, and so far, no information on the influence of the concentrations of substrate and PTC has been reported. In order to obtain the optimum concentration of these PTC, concentration dependent SABRE experiments were conducted in acetone- $\mathrm{d}_{6}$ at $6 \mathrm{mT}$, and the lower substrate concentration limits were determined. The results of these experiments are depicted in Fig. 3. In the case of PTC $3\left(\mathrm{M}=20000 \mathrm{~g} \mathrm{~mol}^{-1}\right)$, the optimum polarization is at a high Py concentration of $45 \mathrm{mM}$ [Fig. 3(a)]. For all three ${ }^{1} \mathrm{H}$-Py signals, enhancements of around $-21 \pm 1$ are achieved. Using PTC 4 signal amplifications of -43 \pm 3 for $o$-Py, $-42 \pm 3$ for $p$-Py, and $-41 \pm 2$ for $m$-Py were realized $\left[\mathrm{c}_{\mathrm{Py}}=23 \mathrm{mM}\right.$, Fig. $\left.3(\mathrm{~b})\right]$. The corresponding concentration curves show that the polarization for this complex is also heavily dependent on the substrate concentration. It is remarkable that signal amplification is feasible for both examined complexes at high Py concentrations.
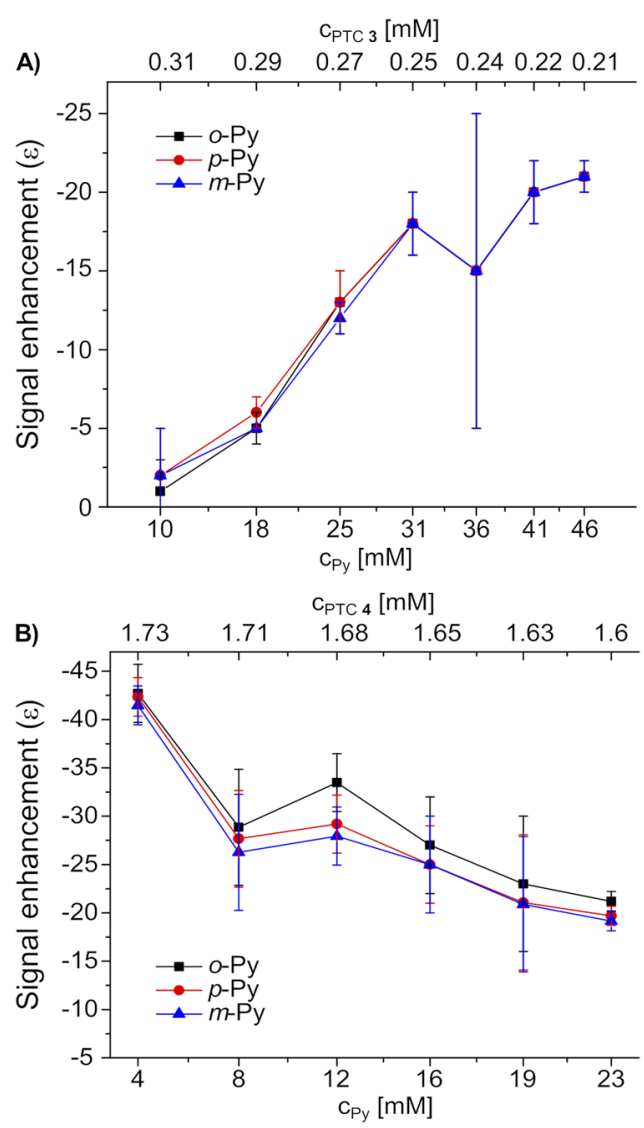

FIG. 3. Concentration dependent SABRE experiments for Py using PTC 3 and PTC 4 conducted in acetone- $\mathrm{d}_{6}$ at $6.6 \mathrm{mT}$. The corresponding concentration curves are depicted in (a) for PTC 3 and in (b) for PTC 4. The optimum polarization is obtained at a Py concentration of $45.6 \mathrm{mM}$ for PTC 3 and $4.1 \mathrm{mM}$ for PTC 4. 
The maximum achieved ${ }^{1} \mathrm{H}$ signal enhancement factors for the novel PTC 2, PTC 3, and PTC 4 in acetone- $\mathrm{d}_{6}$ under the optimal conditions of our setup, as described above, are summarized in Table II. It is remarkable that under these conditions, enhancement factors in the range of the well-known reference PTC 1 can be achieved with PTC 2. In comparison, the enhancements of PTC 3 and PTC $\mathbf{4}$ are considerably lower, but still lie within a range that is suitable for SABRE experiments.

\section{Indications of intermediates in the SABRE spectrum}

Figure 4 shows the SABRE enhanced spectra of the hydride region of the PTC 2, PTC 3, and PTC 4 in acetone- $\mathrm{d}_{6}$ [(a), (b), and (c), respectively]. Interestingly, the spectra of PTC 2 [Fig. 4(a)] and PTC 3 [Fig. 4(b)] reveal several additional hydride signals as compared to the single signal expected from the main species. This is surprising, because if the equatorial plane of the PTC consists of two protons (originating from $\mathrm{pH}_{2}$ ) and two pyridine ligands, as would be expected, only one single hydride signal should be observed. ${ }^{26}$ Here however, we observe two additional species for PTC 2 [Fig. 4(a)] and one for PTC 3 [Fig. 4(b)]. This observation is similar to what we and others ${ }^{19,21,33,47}$ have previously observed for PTC 1, where the additional signals were assigned to low concentrated intermediate complexes, coordinating either $\mathrm{Cl}$ or solvent molecules. ${ }^{19,21,26}$ Indeed, for PTC 2 a hyperpolarized signal of coordinated acetone can be observed [Fig. 4(d)]. As reported in the literature, ${ }^{26,31}$ these intermediates can play a role in the hydrogen exchange cycle. ${ }^{21,47,48}$ Apart from the solubility of $\mathrm{pH}_{2}$, these intermediates could explain increased performance when using a mixture of methanol- $\mathrm{d}_{4}$ and chloroform- $\mathrm{d}_{1}(\mathrm{v} / \mathrm{v}$ 1:1) as a solvent compared to pure chloroform- $\mathrm{d}_{1}$. In the case of PTC 2 , it is also possible that

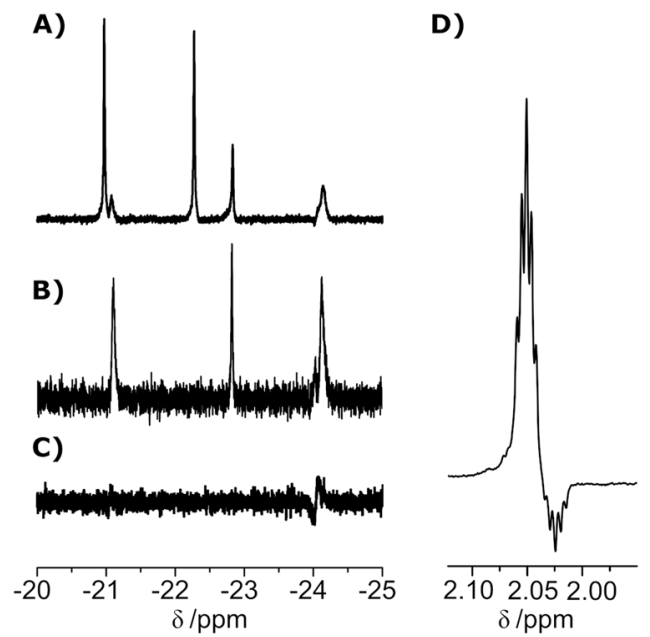

FIG. 4. ${ }^{1} \mathrm{H}-$ SABRE spectra of the hydride region of PTC 2 (a), PTC 3 (b), and PTC 4 (c). In (a) and (b), additional hydride signals compared to a single signal expected from the main species are observed. This could indicate a coordination of $\mathrm{Cl}$ or solvent molecules at the Ir center. For PTC 4 (c) only one hydride signal is observed. In the case for PTC 2, the polarized signal of acetone can be observed at $\sim 2.05 \mathrm{ppm}$ (d). This can be explained by coordination of acetone via the oxygen atom to the Ir center. the oxanorbornene group coordinates to the Ir center via one of its oxygen atoms. For PTC 4, only one hydride signal at $-24 \mathrm{ppm}$ is observed [Fig. 4(c)].

\section{CONCLUSIONS}

The use of NHC ligands and their corresponding Ir-complexes for SABRE as an important hyperpolarization technique continues to expand. In this work, three Ir-NHC complexes were tested as PTC for SABRE experiments to explore another possibility for separating the complex from the substrate. Compared to complexes immobilized on supplementary material, these novel complexes have the advantage of being homogeneous in solution, and therefore appearing as narrow lines in the NMR spectrum. This is particularly interesting for SABRE high-field polarization sequences, where a special defined Larmor frequency is often required to achieve an efficient transfer. ${ }^{31}$ Moreover, they allow for easy access to the metal center (here: Ir) as compared to the immobilized Ir-NHC complexes used in previous studies. ${ }^{28,29}$ The results presented in this paper clearly show that these novel Ir-NHC complexes can realize an efficient SABRE polarization transfer. Finally, an optimization of the SABRE experimental procedure, with respect to the parameters such as solvent, PTF, and the concentration dependence of new complexes and Py was performed.

The results of these optimization studies confirm that all investigated parameters have a significant influence on the efficiency of SABRE experiments.

In particular, the signal amplifications achieved with PTC 2 for $o$-Py $(-158 \pm 8), p$-Py $(-274 \pm 8)$, and $m$-Py $(-262 \pm 8)$ are comparable with those of PTC 1 for $o$-Py $(-286 \pm 6), p$-Py $(-273 \pm 6)$, and $m$-Py $(-273 \pm 6)$ under our conditions, which according to the literature is the most efficient complex for the substrate used here to date. ${ }^{26,31}$ PTC 2 has the core structure of PTC $\mathbf{1}$ (Fig. 1) with a monomer chain (oxanorbornene) at the NHC backbone. ${ }^{1} \mathrm{H}-\mathrm{NMR}$ and ${ }^{1} \mathrm{H}$-SABRE spectra were recorded at room temperature and at a PTF of $6.6 \mathrm{mT}$. This means that despite the modification of the complex by adding the polymerization ligand, sufficient polarization can be transferred to Py.

If the monomer chain of this complex is further developed into a polymer chain, the complex can be separated from the substrate by filtration. Although the signal enhancements achieved for PTC 3 and PTC $\mathbf{4}$ are about one order of magnitude lower, in principle they can still be used as SABRE complexes. Possibly, faster relaxation of the spins in these complexes could explain their lower efficiency. It can also be assumed that due to their sterically demanding NHC ligands, hydrogen and substrate have a different exchange rate in the SABRE experiments. This would be consistent with the abovedescribed observations of a concentration dependence of PTC 3 and PTC 4 (Fig. 3) and reduced signal enhancement by a factor of -21 \pm 1 using PTC 3 and about $-40 \pm 3$ for PTC 4, respectively. Further studies, which are beyond the current paper, are currently in progress.

Furthermore, the effect of the solvent is noticeable. Methanol$\mathrm{d}_{4}$ and acetone- $\mathrm{d}_{6}$ lead to an improved stabilization of the cations and anions present in the reaction solution compared to chloroform- $\mathrm{d}_{1} \cdot{ }^{36}$ We also detect additional hydride signals, which may originate from coordinated solvent molecules (Fig. 4). These 
signals can be detected in the ${ }^{1} \mathrm{H}$-SABRE spectra of PTC 2, PTC 3, and PTC 4. Their presence affects the coordination sphere of Ir during the SABRE experiment and can influence the exchange rates of the target substrate and hydrogen. It is known that the analysis and optimization of the exchange rates in these complexes have a substantial influence on the efficiency of signal amplification. ${ }^{26}$ For this reason, they should be determined in the future.

The ligand structures shown here represent an important step toward biocompatible Ir-NHC complexes for SABRE as the substitution in the NHC backbone offers the possibility to separate the toxic complexes from the solution and from the substrate by nanofiltration, which has been technically realized for large scale volumes. ${ }^{3 .}$ In the future, we will aim to integrate such a filtration step in our experimental setup.

\section{SUPPLEMENTARY MATERIAL}

See the supplementary material for SABRE pulse program, calculation of signal enhancement, and additional spectra.

\section{ACKNOWLEDGMENTS}

This work was supported by the German Research Foundation (DFG) under Contract No. Bu-911-29-1 and the Russian Science Foundation (Grant No. 19-43-04116) in the framework of a joint DFG/RSF collaborative project. S.H. and G.B. thank the state of Hesse for support in the framework of the LOEWE project INAPO.

There are no conflicts to declare.

\section{REFERENCES}

${ }^{1}$ A. S. L. Thankamony, J. J. Wittmann, M. Kaushik, and B. Corzilius, Prog. Nucl, Magn. Reson. Spectrosc. 102, 120-195 (2017).

${ }^{2}$ J. H. Ardenkjaer-Larsen, B. Fridlund, A. Gram, G. Hansson, L. Hansson, M. H. Lerche, R. Servin, M. Thaning, and K. Golman, Proc. Natl. Acad. Sci. U. S. A. 100(18), 10158-10163 (2003).

${ }^{3}$ D. Stehlik and K. H. Hausser, Z. Naturforsch., A 22(6), 914 (1967).

${ }^{4}$ T. Maly, G. T. Debelouchina, V. S. Bajaj, K. N. Hu, C. G. Joo, M. L. Mak-Jurkauskas, J. R. Sirigiri, P. C. A. van der Wel, J. Herzfeld, R. J. Temkin, and R. G. Griffin, J. Chem. Phys. 128(5), 052211 (2008).

${ }^{5}$ C. Griesinger, M. Bennati, H. M. Vieth, C. Luchinat, G. Parigi, P. Hofer, F. Engelke, S. J. Glaser, V. Denysenkov, and T. F. Prisner, Prog. Nucl. Magn. Reson. Spectrosc. 64, 4-28 (2012).

${ }^{6}$ T. Prisner and W. Kockenberger, Appl. Magn. Reson. 34(3-4), 213-218 (2008).

${ }^{7}$ M. A. Bouchiat, T. R. Carver, and C. M. Varnum, Phys. Rev. Lett. 5(8), 373-375 (1960).

${ }^{8}$ T. G. Walker and W. Happer, Rev. Mod. Phys. 69(2), 629-642 (1997).

${ }^{9}$ T. G. Walker, J. H. Thywissen, and W. Happer, Phys. Rev. A 56(3), 2090-2094 (1997).

${ }^{10}$ C. R. Bowers and D. P. Weitekamp, Phys. Rev. Lett. 57(21), 2645-2648 (1986).

${ }^{11}$ C. R. Bowers and D. P. Weitekamp, J. Am. Chem. Soc. 109(18), 5541-5542 (1987).

${ }^{12}$ M. G. Pravica and D. P. Weitekamp, Chem. Phys. Lett. 145(4), 255-258 (1988).

${ }^{13}$ G. Buntkowsky, J. Bargon, and H. H. Limbach, J. Am. Chem. Soc. 118(36), 8677-8683 (1996).

${ }^{14}$ J. Natterer and J. Bargon, Prog. Nucl. Magn. Reson. Spectrosc. 31, 293-315 (1997).

${ }^{15}$ R. W. Adams, J. A. Aguilar, K. D. Atkinson, M. J. Cowley, P. I. P. Elliott, S. B. Duckett, G. G. R. Green, I. G. Khazal, J. Lopez-Serrano, and D. C. Williamson, Science 323(5922), 1708-1711 (2009).
${ }^{16}$ R. W. Adams, S. B. Duckett, R. A. Green, D. C. Williamson, and G. G. R. Green, J. Chem. Phys. 131(19), 194505 (2009).

${ }^{17}$ K. D. Atkinson, M. J. Cowley, P. I. P. Elliott, S. B. Duckett, G. G. R. Green, J. Lopez-Serrano, and A. C. Whitwood, J. Am. Chem. Soc. 131(37), 13362-13368 (2009).

${ }^{18}$ J. B. Hovener, A. N. Pravdivtsev, B. Kidd, C. R. Bowers, S. Gloggler, K. V. Kovtunov, M. Plaumann, R. Katz-Brull, K. Buckenmaier, A. Jerschow, F. Reineri, T. Theis, R. V. Shchepin, S. Wagner, P. Bhattacharya, N. M. Zacharias, and E. Y. Chekmenev, Angew. Chem., Int. Ed. 57(35), 11140-11162 (2018).

${ }^{19}$ M. J. Cowley, R. W. Adams, K. D. Atkinson, M. C. R. Cockett, S. B. Duckett, G. G. R. Green, J. A. B. Lohman, R. Kerssebaum, D. Kilgour, and R. E. Mewis, J. Am. Chem. Soc. 133(16), 6134-6137 (2011).

${ }^{20}$ A. S. Kiryutin, G. Sauer, D. Tietze, M. Brodrecht, S. Knecht, A. V. Yurkovskaya, K. L. Ivanov, O. Avrutina, H. Kolmar, and G. Buntkowsky, Chem. - Eur. J. 25(16), 4025-4030 (2019).

${ }^{21}$ S. Knecht, S. Hadjiali, D. A. Barsiciy, A. Pines, G. Sauer, A. S. Kiryutin, K. L. Ivanov, A. V. Yurkoyskaya, and G. Buntkowsky, J. Phys. Chem. C 123(26), 16288-16293 (2019).

${ }^{22}$ G. Sauer, D. Nasu, D. Tietze, T. Gutmann, S. Englert, O. Avrutina, H. Kolmar, and G. Buntkowsky, Angew. Chem., Int. Ed. 53(47), 12941-12945 (2014).

${ }^{23}$ M. Korner, G. Sauer, A. Heil, D. Nasu, M. Empting, D. Tietze, S. Voigt, H. Weidler, T. Gutmann, O. Avrutina, H. Kolmar, T. Ratajczyk, and G. Buntkowsky, Chem. Commun. 49(71), 7839-7841 (2013).

${ }^{24}$ T. Theis, N. M. Ariyasingha, R. V. Shchepin, J. R. Lindale, W. S. Warren, and E. Y. Chekmenev, J. Phys. Chem. Lett. 9(20), 6136-6142 (2018).

${ }^{25}$ T. Theis, M. L. Truong, A. M. Coffey, R. V. Shchepin, K. W. Waddell, F. Shi, B. M. Goodson, W. S. Warren, and E. Y. Chekmenev, J. Am. Chem. Soc. 137(4), 1404-1407 (2015).

${ }^{26}$ P. J. Rayner and S. B. Duckett, Angew. Chem., Int. Ed. 57(23), 6742-6753 (2018).

${ }^{27}$ B. E. Kidd, J. L. Gesiorski, M. E. Gemeinhardt, R. V. Shchepin, K. V. Kovtunov, I. V. Koptyug, E. Y. Chekmenev, and B. M. Goodson, J. Phys. Chem. C 122(29), 16848-16852 (2018).

${ }^{28}$ F. Shi, A. M. Coffey, K. W. Waddell, E. Y. Chekmenev, and B. M. Goodson, Angew. Chem., Int. Ed. 53(29), 7495-7498 (2014).

${ }^{29}$ K. V. Kovtunov, L. M. Kovtunova, M. E. Gemeinhardt, A. V. Bukhtiyarov, J. Gesiorski, V. I. Bukhtiyarov, E. Y. Chekmenev, I. V. Koptyug, and B. M. Goodson, Angew. Chem., Int. Ed. 56(35), 10433-10437 (2017).

${ }^{30}$ D. A. Barskiy, L. A. Ke, X. Y. Li, V. Stevenson, N. Widarman, H. Zhang, A. Truxal, and A. Pines, J. Phys. Chem. Lett. 9(11), 2721-2724 (2018).

${ }^{31}$ D. A. Barskiy, S. Knecht, A. V. Yurkovskaya, and K. L. Ivanov, Prog. Nucl. Magn. Reson. Spectrosc. 114-115, 33-70 (2019).

${ }^{32}$ S. Hadjiali, R. Savka, M. Plaumann, U. Bommerich, S. Bothe, T. Gutmann, T. Ratajczyk, J. Bernarding, H. H. Limbach, H. Plenio, and G. Buntkowsky, Appl. Magn. Reson. 50(7), 895-902 (2019).

${ }^{33}$ L. S. Lloyd, A. Asghar, M. J. Burns, A. Charlton, S. Coombes, M. J. Cowley, G. J. Dear, S. B. Duckett, G. R. Genov, G. G. R. Green, L. A. R. Highton, A. J. J. Hooper, M. Khan, I. G. Khazal, R. J. Lewis, R. E. Mewis, A. D. Roberts, and A. J. Ruddlesden, Catal. Sci. Technol. 4(10), 3544-3554 (2014).

${ }^{34}$ M. Bergmann, M. Egert, and H. Plenio, Chem. - Eur. J. 23(54), 13328-13331 (2017).

${ }^{35}$ D. Schoeps, K. Buhr, M. Dijkstra, K. Ebert, and H. Plenio, Chem. - Eur. J. 15(12), 2960-2965 (2009).

${ }^{36}$ D. A. Barskiy, A. N. Pravdivtsev, K. L. Ivanov, K. V. Kovtunov, and I. V. Koptyug, Phys. Chem. Chem. Phys. 18(1), 89-93 (2016).

${ }^{37}$ R. Savka and H. Plenio, Dalton Trans. 44(3), 891-893 (2015).

${ }^{38}$ A. S. Kiryutin, G. Sauer, S. Hadjiali, A. V. Yurkovskaya, H. Breitzke, and G. Buntkowsky, J. Magn. Reson. 285, 26-36 (2017).

${ }^{39}$ C. Descamps, C. Coquelet, C. Bouallou, and D. Richon, Thermochim. Acta 430(1-2), 1-7 (2005).

${ }^{40}$ Purwanto, R. M. Deshpande, R. V. Chaudhari, and H. Delmas, J. Chem. Eng. Data 41(6), 1414-1417 (1996).

${ }^{41}$ E. B. Ducker, L. T. Kuhn, K. Munnemann, and C. Griesinger, J. Magn. Reson. 214, 159-165 (2012). 
${ }^{42}$ R. E. Mewis, R. A. Green, M. C. R. Cockett, M. J. Cowley, S. B. Duckett, G. G. R. Green, R. O. John, P. J. Rayner, and D. C. Williamson, J. Phys. Chem. B 119(4), 1416-1424 (2015).

${ }^{43}$ M. Fekete, P. J. Rayner, G. G. R. Green, and S. B. Duckett, Magn, Reson. Chem. 55(10), 944-957 (2017).

${ }^{44} \mathrm{M}$. Fekete, O. Bayfield, S. B. Duckett, S. Hart, R. E. Mewis, N. Pridmore, P. J. Rayner, and A. Whitwood, Inorg. Chem. 52(23), 13453-13461 (2013).
${ }^{45}$ A. N. Pravdivtsev, K. L. Ivanov, A. V. Yurkovskaya, P. A. Petrov, H. H. Limbach, R. Kaptein, and H. M. Vieth, J. Magn. Reson. 261, 73-82 (2015).

${ }^{46}$ A. N. Pravdivtsev, A. V. Yurkovskaya, H. M. Vieth, K. L. Ivanov, and R. Kaptein, ChemPhysChem 14(14), 3327-3331 (2013).

${ }^{47}$ S. Knecht, A. S. Kiryutin, A. V. Yurkovskaya, and K. L. Ivanov, J. Magn. Reson. 287, 74-81 (2018).

${ }^{48}$ A. S. Kiryutin, G. Sauer, A. V. Yurkovskaya, H. H. Limbach, K. L. Ivanov, and G. Buntkowsky, J. Phys. Chem. C 121(18), 9879-9888 (2017).

This article may be downloaded for personal use only. Any other use requires prior permission of the author and AIP Publishing. This article appeared in The Journal of Chemical Physics 151 (2019) 24 and may be found at https://doi.org/10.1063/1.5128091.

Available under only the rights of use according to UrhG. 